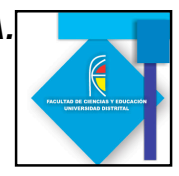

\title{
MATEMATIZACION DEL CENTRO DE MASA A PARTIR DE UNA APLICACIÓN EN LA INGENIERIA.
}

\author{
MATHEMATIZATION CENTER OF MASS FROM AN \\ APPLICATION IN ENGINEERING
}

\begin{abstract}
Oscar Javier Vija Suárez ${ }^{1}$
Resumen

Ingrid Yurani Castellanos Ortegón ${ }^{2}$.

La comprensión de conceptos de física se hace primordial en campos aplicados a esta ciencia, la ingeniera es un campo de vital importancia para el desarrollo de la sociedad y la evolución de la misma, su importancia radica en la aportación que este pueda generar industrial y tecnológicamente. En particular se encuentra que existen dificultades en la conceptualización de centro de masa de un sistema, pues casi siempre se asocia con centro de gravedad. El presente trabajo es una propuesta didáctica para enseñar el concepto de centro de masa generando en el estudiante un pensamiento físicomatemático que garantice una apropiación y correcta aplicación del mismo. La propuesta se basa en un proceso de evolución de imágenes formada por el estudiante llamado "matematización", que hace énfasis en la matemática de las interpretaciones físicas, no como un simple desarrollo de algoritmos sino como una herramienta suficiente y necesaria para explicar los fenómenos de la naturaleza de forma coherente.
\end{abstract}

Palabras clave: Centro de masa, didáctica de la física, pensamiento físico-matemático, matematización, clases de imágenes.

\section{Abstract}

The understanding of concepts of physics are of prime importance in applied fields of this science, engineering is a field of vital importance for the development of society and the evolution of the same, its importance lies in the contribution this can generate industrial and technologically. In particular we find that there are difficulties in the conceptualization of the center of mass of a system, it is almost always associated with center of gravity. This paper is a didactic approach to teach the concept of center of mass student-generated physical-mathematical thinking to ensure a proper appropriation and utilization. The proposal is based on a process of evolution of images formed by the student named "mathematization", which focuses on the mathematics of physical interpretations, not as a simple algorithm development tool but as a necessary and sufficient to explain the phenomena of nature consistently.

\footnotetext{
${ }^{1}$ Universidad Distrital Francisco José de Caldas, yurasipark@gmail.com

${ }^{2}$ Universidad Distrital Francisco José de Caldas, yurasipark@gmail.com
} 


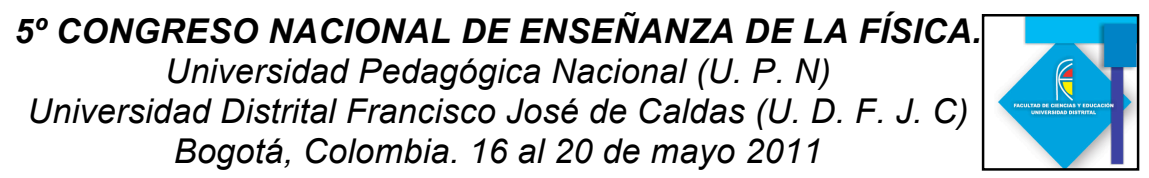

Key words: Center of Mass, teaching physics, physical-mathematical thinking, mathematization, types of images.

\section{Introducción}

En el papel del docente de las ciencias se hace necesaria una constante investigación sobre los procesos de enseñanza y aprendizaje, esto es más relevante en el docente de física, ya que esta necesita más abstracción para entenderla, debido a esto se ha creado nuevas ciencias que se encargan de realizar una constante investigación en el ámbito didáctico para enseñarlas, proponiendo bases para que el docente construya su propio camino logrando alcanzar la enseñanza de una mejor manera.

Uno de los principales problemas actualmente en la educación en física, radica en el pensamiento de los estudiantes acerca de la misma, ya que ellos consideran esta rama de las ciencias tan abstracta que la reducen simplemente a la memorización de formulas dejando de un lado el verdadero sentido que conlleva esta, por ende el docente está en la obligación de hallar estrategias para cambiar dicho pensamiento.

Hoy en día la investigación en la didáctica de la física está tomando más fuerza, pues se han realizado estudios como, los artículos "La relación física matemática desde Dirac" y ¿Qué es didáctica de la Física?, por Castellanos O, Vizcaino. En la X Conferencia Interamericana de Educación. Medellín. 2009. Donde en este se define a la didáctica de la física, como una nueva ciencia encargada de buscar nuevas estrategias para mejorar la enseñanza y propone al didacta como el principal generador de esta investigación.

Con el fin de brindar innovación y actualización en dichos procesos en pro de su mejoramiento, en este trabajo se presenta una propuesta didáctica donde se muestra una forma de abordar un concepto físico, logrando generar en el estudiante un pensamiento físico matemático por medio de imágenes y representaciones formadas por los mismos, pues es de vital importancia tener en cuenta que cada persona tiene formas diferentes de abstraer el conocimiento, ya que sus modelos mentales son diferentes de acuerdo a sus representaciones y previsiones que le permiten explicarlo, en cuanto a los modelos conceptuales "son los modelos proyectados por físicos, ingenieros, profesores, para facilitar la comprensión y la enseñanza de sistemas físicos o fenómenos naturales, es decir profesores y alumnos trabajan con modelos mentales, pero intentan enseñar y aprender modelos conceptuales" (Moreira y Greca,2002) dichos modelos conceptuales son los que debemos tener muy presente a la hora de enseñar, ya que es lo que quedara en la mente del estudiante y por tanto debemos hacer el esfuerzo posible para que dicho modelo sea el correcto, esto lo logramos planteando estrategias diferentes para no recaer en la enseñanza habitual "poniendo en duda que la transmisión de conocimientos elaborados haga una recepción significativa de los mismos" (Gil, 2005) para lo cual es necesaria la previa auto investigación mencionada anteriormente.

Esta propuesta se desarrolla en base a la experiencia propia de los autores de este trabajo. Se procede a realizar una consulta acerca de este concepto construyendo 


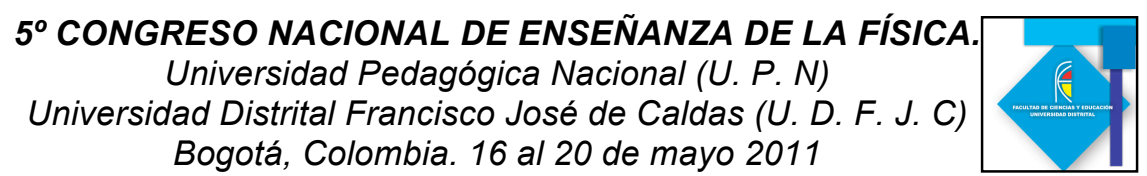

imágenes propias y a medida de que surja la necesidad de cambiar la imagen que se tiene por su falta de argumentación se hace una profundización del mismo por medio de un proceso llamado matematización (Vizcaino y Castiblanco, 2009)

\section{Sobre la didáctica de la física.}

La didáctica de la física se toma como una ciencia encargada de investigar formas de enseñanza y aprendizaje de la física, partiendo del hecho de que para poder enseñar un tema se debe tener dominio total en este, Esta ciencia propone al docente realizar una investigación que le permita evaluar su estado del conocimiento que posteriormente transmitirá, el proceso antes mencionado asegura que el docente tenga la capacidad de generar el pensamiento físico-matemático y por tanto tener la capacidad de abordar el tema de una forma correcta.

\section{Desarrollo de la Propuesta.}

La propuesta se desarrolla teniendo en cuenta la torre inclinada de Pizza generando la pregunta del ¿Por qué esta no se cae? Cuya solución se apoya en la definición del centro de masa que proporcionan algunos textos especializados en el tema como es el caso de la física general de Paul Tipler, en el cual se menciona que, "es un punto que se mueve como si en él estuviera concentrada toda la masa del sistema y las fuerzas externas del sistemas se aplican exclusivamente en dicho punto" (Tipler, 1977) de acuerdo a lo definido en este libro, se puede explicar que esa estructura no se cae debido a que el centro de masa no se encuentra fuera ni en la parte alta de la misma, se hace pertinente la matematización, ya que, se requiere una evolución del pensamiento físico, pues donde se encontrara una estructura curva como un toroide, se interpretaría como una representación o coordenada espacial donde actúa una fuerza externa, sin embargo al indagar la definición se llega a la necesidad de completarla debido a que surge la duda de ¿cómo puede ser una fuerza aplicada en el vacío y esta a su vez modificar el estado de un sistema?.

Analizando la física de la torre se logran hallar dos puntos llamados puntos de equilibrio donde estos realmente limitan la ubicación del centro de masa, es decir que no es necesario que dicho centro quede dentro de la estructura, por lo tanto si aplicamos una fuerza fuera del rango de distancias entre los puntos de equilibrio la estructura presentara un torque causando su rotación.

Dicho conocimiento es logrado debido al proceso de matematización aplicado en la comprensión del concepto de centro de masa, que matemáticamente está definida como la sumatoria de los diferenciales de la masa que constituye la estructura por la posición en la que se encuentra cada diferencial dividida entre la masa total de esta, donde la interpretación física de lo anterior resulta ser que el centro de masa es el punto promedio de toda la masa de la estructura, en otras palabras es como si toda la masa estuviera concentrada en dicho punto. 


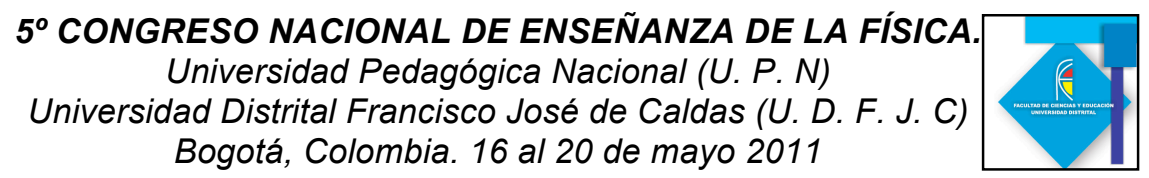

Teniendo en cuenta lo anterior, la propuesta de la matematización resulta ser la sustentación del formulismo matemático por medio de una transformación del lenguaje técnico al lenguaje manejado por el lector, de tal forma que él pueda construir y comprender su propio concepto lo cual es un paso necesario para generar un pensamiento físico-matemático.

\section{Conclusiones}

La investigación en didáctica de la fisca, tiene como fin mejorar la educación y la percepción de esta asignatura, esta nueva ciencia logra incentivar no solo a la investigación de procesos de enseñanza, también incentiva formas de profundizar en temas de física y logar nuevas formas de ver esta.

El analizar la ecuación matemática que representa el significado de un concepto, en este caso del centro de masa, desde el punto de vista físico evidencia la relación que hay entre la matemática y la física, lo cual puede ser tomado como basa para acabar con la idea errónea del estudiante de separarlas.

El proceso desarrollado en este trabajo dejo a la luz el por qué se dice que el lenguaje de la física es la matemática, pues la matemática logra sintetizar y generalizar las interpretaciones físicas de un fenómeno, solo que al momento de explicarlo no se tienen en cuenta estas interpretaciones, por este motivo se ha considerado de manera equivoca que la física solo consiste en aprender a aplicar las ecuaciones.

Las aplicaciones de un concepto resultan ser la mejor introducción de un tema, ya que el estudiante por medio de estas, puede construir sus propias imágenes acerca de este generando la confianza de defender sus ideas hasta que su propia coherencia se lo permita. En el caso del centro de masa fue de gran ayuda utilizar la estructura de la torre de pizza, pues en esta estructura se evidencia, la necesidad de tener presente el centro de masa para que una estructura no colapse.

\section{Bibliografía}

MOREIRA, M., y GRECA, I., (2002) Modelos Mentales y Modelos Conceptuales en la Enseñanza Aprendizaje de las Ciencias.En: Revista Brasileira de Pesquisa em Educação em Ciências. Nº 3, Vol. 2 (2002). Pág. 32-52.

GIL, D., (2005) ¿Cómo Promover el Interés por la Cultura Científica? Una propuesta didáctica fundamentada para la educación científica de jóvenes de 15 a 18 años. Ed. UNESCO. Pág. 459.

VIZCAÍNO, D., y CASTIBLANCO, O.,(2009). Imágenes permisibles, correctas y pertinentes en el pensamiento físico matemático. Universidad Distrital Francisco José de Caldas.

TIPLER, Paul. (1977) Física. Editorial Reverté. España. Pág. 180 